OPEN ACCESS

Edited by:

Guey-Shin Wang,

Academia Sinica, Taiwan

Reviewed by:

Satpal Singh,

University at Buffalo, USA

Lucia Ciranna,

University of Catania, Italy

*Correspondence:

Peng Jin

peng.jin@emory.edu

Yan Jin

jinyan20140104@sina.com

†These authors have contributed equally to this work.

Received: 03 January 2017 Accepted: 18 April 2017

Published: 05 May 2017

Citation:

Kong HE, Zhao J, XU S, Jin P and Jin Y (2017) Fragile X-Associated Tremor/Ataxia Syndrome: From Molecular Pathogenesis to Development of Therapeutics. Front. Cell. Neurosci. 11:128. doi: 10.3389/fncel.2017.00128

\section{Fragile X-Associated Tremor/Ataxia Syndrome: From Molecular Pathogenesis to Development of Therapeutics}

\author{
Ha Eun Kong ${ }^{1 \dagger}$, Juan $\mathrm{Zhao}^{2 \dagger}$, Shunliang $\mathrm{Xu}^{3}$, Peng Jin ${ }^{1 *}$ and Yan $\mathrm{Jin}^{4 *}$ \\ ${ }^{1}$ Department of Human Genetics, School of Medicine, Emory University, Atlanta, GA, USA, ${ }^{2}$ The State Key Laboratory of \\ Medical Genetics, School of Life Sciences, Central South University, Changsha, China, ${ }^{3}$ Department of Neurology, 2nd \\ Hospital of Shandong University, Jinan, China, ${ }^{4}$ Department of Ophthalmology, Second Hospital, Jilin University, Changchun, \\ China
}

Fragile X-associated tremor/ataxia syndrome (FXTAS) is a neurodegenerative disorder caused by a premutation CGG repeat expansion (55-200 repeats) within the 5' UTR of the fragile $X$ gene (FMR1). FXTAS is characterized by intension tremor, cerebellar ataxia, progressive neurodegeneration, parkinsonism and cognitive decline. The development of transgenic mouse and Drosophila melanogaster models carrying an expanded CGG repeat has yielded valuable insight into the pathophysiology of FXTAS. To date, we know of two main molecular mechanisms of this disorder: (1) a toxic gain of function of the expanded CGG-repeat FMR1 mRNA, which results in the binding/sequestration of the CGG-binding proteins; and (2) CGG repeat-associated non-AUG-initiated (RAN) translation, which generates a polyglycine peptide toxic to cells. Besides these CGG-mediated mechanisms, recent studies have shed light on additional mechanisms of pathogenesis, such as the antisense transcript ASFMR1, mitochondrial dysfunction, DNA damage from R-loop formation and 5-hydroxymethylcytosine (5hmC)-mediated epigenetic modulation. Here we summarize the recent progress towards understanding the etiology of FXTAS and provide an overview of potential treatment strategies.

Keywords: FXTAS pathogenesis, CGG repeat, RNA toxicity, RAN translation, FXTAS therapeutics

\section{INTRODUCTION}

Fragile X-associated tremor/ataxia syndrome (FXTAS) is a neurodegenerative disorder caused by a CGG triplet repeat expansion within the $5^{\prime}$ UTR of FMR1. Normally, individuals possess between 5 and 54 CGG repeats, and full mutation CGG repeats greater than 200 lead to the neurodevelopmental disease fragile X syndrome (FXS), which results from the excessive methylation of FMR1 and loss of FMRP protein (Kremer et al., 1991; Verkerk et al., 1991; Hagerman and Hagerman, 2002; Colak et al., 2014). Individuals with 55-200 CGG repeats are referred to as premutation carriers (Cronister et al., 2008).

Over a third of male expanded CGG repeat premutation carriers develop FXTAS later in adulthood (Jacquemont et al., 2004), whereas female premutation carriers may develop fragile X-associated primary ovarian insufficiency (FXPOI; Rodriguez-Revenga et al., 2009). Random X-inactivation is believed to protect female carriers from developing FXTAS, leading to relatively few female FXTAS patients (Hagerman et al., 2004; Zühlke et al., 2004; Coffey et al., 2008). 
Clinically, FXTAS presents with intention tremor, gait ataxia, and other features including parkinsonism, cognitive defects, brain atrophy and white matter abnormalities on MRI (Jacquemont et al., 2003; Hagerman and Hagerman, 2015). Neuropathologically, FXTAS is distinguished by the characteristic ubiquitin-positive intranuclear inclusions in the brain and spinal cord as well as peripheral tissues (Greco et al., 2002, 2006; Gokden et al., 2009; Hunsaker et al., 2011).

Animal models have played a critical role in revealing the mechanisms of FXTAS pathogenesis. FXTAS mouse and Drosophila melanogaster models effectively mimic the molecular and cellular alterations and clinical symptoms of FXTAS. Several knock-in and transgenic mouse models are available for studying various aspects of FXTAS pathology (Bontekoe et al., 2001; Peier and Nelson, 2002; Entezam et al., 2007; Hashem et al., 2009). Aside from obviously elevated FMR1 mRNA levels, reduced FMRP expression, and intranuclear inclusion formation, mouse models of FXTAS also exhibit abnormal dendritic spine morphology, impaired motor coordination, and cognitive deficits, recapitulating many features of FXTAS patients (Bontekoe et al., 2001; Willemsen et al., 2003; Entezam et al., 2007; Hunsaker et al., 2009; Hukema et al., 2015). In flies, the FXTAS transgenic Drosophila model expressing 90 CGG repeats displays locomotor deficits and retinal degeneration (Jin et al., 2003). Animal models allow researchers to investigate pathological mechanisms of FXTAS, identify potential modifiers, and pursue treatment development.

The two widely accepted mechanisms for the pathogenesis of FXTAS are RNA toxicity and repeat associated non-AUG translation (RAN) protein toxicity (via RAN). Several lines of evidence support the RNA toxicity mechanism. First, older adults with the full mutation ( $>200$ repeats), who do not express FMR1 mRNA and lack FMRP, do not develop FXTAS (Feng et al., 1995). Second, in FXTAS, there is significant upregulation (2-8 fold) of the expanded CGG-repeat FMR1 mRNA, resulting in formation of nuclear RNA aggregates. These aggregates sequester rCGG-binding proteins, preventing them from performing their normal biological functions, such as mRNA transcription and splicing, as well as dendritic mRNA transport (Tassone et al., 2000; Kenneson et al., 2001; Pretto et al., 2014). The level of FMR1 protein in cells from premutation carriers, however, remains relatively unaltered (Tassone et al., 2000; Kenneson et al., 2001). Third, FMR1 RNA is present in the intranuclear inclusions of postmortem FXTAS brain tissue (Tassone et al., 2004), and animal and cell models expressing rCGG repeats develop similar inclusions (Jin et al., 2003; Willemsen et al., 2003; Arocena et al., 2005). But RNA toxicity alone is not sufficient to account for the large ubiquitin-positive intranuclear inclusions in the brains of FXTAS patients, a neuropathological hallmark of the disease. In fact, in addition to the RNA-binding proteins (RBPs), these inclusions contain proteins that do not bind to CGG-repeat mRNA and are reminiscent of the neuronal intranuclear inclusions found in protein-mediated neurodegenerative disorders and polyglutamine diseases (Greco et al., 2006; Iwahashi et al., 2006; Williams and Paulson, 2008). In light of this, a proteindriven mechanism of FXTAS pathogenesis was uncovered, in which the premutation CGG repeat expansion was found to induce RAN translation within the $5^{\prime}$ UTR of FMR1 mRNA via an AUG-independent mechanism (Todd et al., 2013). The resulting polyglycine-containing protein, FMRpolyG, is present in the brains of FXTAS patients and was found to be toxic to human cell lines as well as Drosophila neurons, leading to retinal degeneration in FXTAS Drosophila (Todd et al., 2013).

To date, CGG repeat-mediated RNA toxicity and RAN protein toxicity stand as the two most important mechanisms in FXTAS pathophysiology, leading to the sequestration of specific proteins and the generation of the toxic protein product FMRpolyG, respectively. Besides these two main mechanisms, others have been uncovered, such as antisense FMR1 RNA (Ladd et al., 2007), epigenetic modulation, mitochondrial dysfunctions (Hukema et al., 2014) and R-loop-induced DNA damage response (Loomis et al., 2014). In this review article, we summarize the current understanding of the underlying mechanisms of FXTAS and discuss potential therapeutic strategies.

\section{RNA-MEDIATED FXTAS PATHOGENESIS VIA RBP SEQUESTRATION}

A defining molecular signature of FXTAS is the elevation of premutation FMR1 mRNA levels with no detectable or only a modest reduction in FMRP protein levels (Tassone et al., 2000; Kenneson et al., 2001; Pretto et al., 2014). Along with the presence of FMR1 mRNA in ubiquitin-positive intranuclear inclusions of FXTAS patient brains, these observations point to a toxic RNA gain-of-function mechanism for FXTAS pathogenesis, which could lead to sequestration of various rCGG repeat-binding proteins (Tassone et al., 2004).

Using mass spectrometric analysis combined with immunohistochemical analysis, more than 20 proteins have been identified in inclusions in the frontal cortex of FXTAS patients, including RBPs hnRNP A2/B1 and MBNL1, and some neurofilament proteins, such as lamin $\mathrm{A} / \mathrm{C}$ and $\alpha$ internexin, which are involved in various neurological disorders (Iwahashi et al., 2006). Pur $\alpha$ and hnRNP A2/B1 are found to bind directly to rCGG repeats in inclusions. In fact, in a Drosophila model expressing premutation CGG repeat expansions, overexpression of Pur $\alpha$ and hnRNP A2/B1 leads to suppression of neurodegeneration phenotypes (Jin et al., 2007; Sofola et al., 2007). Sequestration of other proteins, such as CUGBP1, Sam68, Rm62 and DGCR8, leads to altered mRNA splicing and transport, as well as dysregulated microRNAs (Sofola et al., 2007; Sellier et al., 2010, 2013; Qurashi et al., 2011; Tan et al., 2012a). These findings support a toxic RNA gain-of-function mechanism, which is mediated by the expanded CGG repeats in FMR1.

Heterogeneous nuclear ribonucleoprotein (hnRNP A2/B1) is an RBP noted for its presence in intranuclear inclusions of FXTAS patients. hnRNP A2/B1 has been shown to bind directly to rCGG repeats and, interestingly, overexpression of hnRNP A2/B1 and its two homologs in Drosophila results in suppression of the neurodegenerative eye phenotype caused by the rCGG repeat (Sofola et al., 2007). hnRNP A2/B1 is also 
known to mediate the indirect interaction between CGG repeats and CUGBP1, a RBP noted for its binding of CUG repeats and involvement in myotonic dystrophy type 1 (DM1; Timchenko et al., 1996, 2001, 2004). Overexpression of CUGBP1 also suppresses the FXTAS phenotype in Drosophila (Sofola et al., 2007). Moreover, Muslimov et al. (2011) found that premutation CGG-repeat RNA binds competitively to hnRNP A2/B1 and leads to the alteration of neuronal RNA dendritic transport, which can be partially reversed by overexpression of hnRNP A2. Furthermore, our group has shown that in a Drosophila model, rCGG repeats trigger the activation of certain retrotransposons, such as gypsy. We also demonstrated that hnRNP A2/B1 may regulate the activation of gypsy by recruiting heterochromatin protein 1 (HP1) for transposon silencing. As a result, in FXTAS, the expanded rCGG repeats may sequester hnRNP A2/B1 and diminish the recruitment of HP1 to genomic regions containing retrotransposons, further contributing to retrotransposon activation (Tan et al., 2012b). Significantly, we also found that hnRNP A2/B1 regulates expression of miR277, a miRNA that, when overexpressed, results in enhancement of rCGG repeat-mediated neurodegeneration (Tan et al., 2012a).

Also present in intranuclear inclusions of FXTAS patients, Pur $\alpha$ is an RNA- and specific single-stranded DNA-binding protein that plays an essential role in DNA replication, neuronal mRNA transport, and translation. Pur $\alpha$ knockout mice display developmental delay along with severe tremor and spontaneous seizures at 2 weeks after birth, and the expression and distribution of axonal and dendritic proteins are also altered (Khalili et al., 2003; Hokkanen et al., 2012). Similar to hnRNP A2/B1, Pur $\alpha$ has been implicated in FXTAS pathogenesis due to the fact that overexpression of Pur $\alpha$ in a Drosophila model results in dose-dependent suppression of rCGG-mediated neurodegeneration.

Probing the Pur $\alpha$ interactome has also led to the identification of $\mathrm{Rm} 62$ as a possible mediator of FXTAS pathogenesis. Rm62 was identified via a proteomic approach as a potential regulator of rCGG-mediated neurodegeneration (Qurashi et al., 2011). Rm62 is the Drosophila ortholog of p68 RNA helicase, a transcriptional regulator that is also involved in pre-mRNA splicing, RNA interference and nucleocytoplasmic shuttling (Bond et al., 2001; Ishizuka et al., 2002; Liu, 2002; Wilson et al., 2004; Lin et al., 2005). In FXTAS Drosophila, rCGG repeats diminish posttranscriptional expression of Rm62, and overexpression of Rm62 can suppress the neuronal toxicity caused by the premutation rCGG repeats (Qurashi et al., 2011). The decrease in Rm62 expression in turn leads to the nuclear accumulation of mRNAs involved in stress and immune responses, as well as the accumulation of $H s p 70$ mRNA, a target of Rm62 (Qurashi et al., 2011), which has actually been found in inclusions from both human FXTAS brains and animal models of FXTAS (Jin et al., 2003).

The alternative splicing regulator Src-Associated substrate during mitosis of $68-\mathrm{kDa}$ (Sam68) is another RBP shown to be sequestered by rCGG repeats. One study revealed that Sam68 colocalizes with the giant dynamic aggregates that form from mRNAs containing expanded CGG repeats in both premutation CGG-expressing cells and FXTAS patient brain sections (Sellier et al., 2010). The sequestration of Sam68 results in the loss of its ability to perform splicing regulation and causes pre-mRNA alternative splicing misregulation in CGG-transfected cells and FXTAS patients (Sellier et al., 2010). Sam68 localization is regulated by tyrosine phosphorylation, and the phosphatase inhibitor tautomycin was shown to prevent aggregation of both Sam68 and CGG RNA (Sellier et al., 2010). Taken together, the sequestration of Sam68 must play a role in FXTAS pathogenesis via a splicing alteration mechanism.

TAR DNA-binding protein (TDP-43) is an amyotrophic lateral sclerosis (ALS)-associated RBP, a marker of neurodegeneration commonly found in inclusions in ALS (Baloh, 2012). In the cerebellar Purkinje neurons of mice expressing 90 CGG repeats, the mRNA for Tardbp, which encodes TDP-43, showed a reduced association with ribosomes (Galloway et al., 2014). In the same study, the authors went on to find that in the Drosophila model of FXTAS, wild-type TDP-43 expression leads to suppression of neurodegeneration, while knockdown of the endogenous TDP-43 fly ortholog, TBPH, enhanced the eye phenotype. Another study also independently reported that TDP-43 suppresses CGG repeat-induced toxicity in a Drosophila model of FXTAS (He et al., 2014). Interestingly, this suppression was shown to depend on hnRNP A2/B1, such that deletion of the C-terminal domain of TDP-43 and thereby the prevention of interactions with hnRNP A2/B1 led to abrogation of the TDP-43-dependent rescue of CGG repeat toxicity ( $\mathrm{He}$ et al., 2014).

The DiGeorge syndrome critical region 8 (DGCR8) is yet another protein reported to bind to premutation rCGG repeats and cause partial sequestration of DGCR8 and its partner, DROSHA, within the premutation RNA aggregates (Sellier et al., 2013). DGCR8 and DROSHA play a critical role in microRNA biogenesis. In the first step of microRNA biogenesis, RNA polymerase II transcribes miRNAs as primary miRNA (primiRNA) transcripts. DROSHA, a type III RNase, is anchored to the pri-miRNA by DGCR8, and processes pri-miRNA into precursor miRNA (pre-miRNA; Lee et al., 2003; Denli et al., 2004; Gregory et al., 2004; Han et al., 2004; Landthaler et al., 2004). Sellier et al. (2013) found that the sequestration of DGCR8 and DROSHA precludes them from their normal functions, leading to reduced processing of pri-miRNAs in cells expressing expanded CGG repeats and also in the brains of FXTAS patients. Consequently, levels of mature miRNAs are reduced (Sellier et al., 2013). The authors also found evidence that sequestration of SAM68 in the CGG aggregates is mediated through DROSHA or DGCR8, but restoration of SAM68 function is not sufficient to restore all normal neuronal cell functions. In contrast, expression of DGCR8 alone in cultured premutation mouse cortical neurons could rescue their dendritic morphological abnormalities and diminished neuronal viability. This work suggested a model for the mechanism of FXTAS pathogenesis in which sequestration of the DROSHADGCR8 microprocessor by expanded rCGG repeats may lead to reduced mature miRNA expression, resulting in neuronal cell dysfunction and degeneration. 
In summary, we have presented a broad overview of the RBPs that are sequestered via the RNA toxicity mechanism, as well as our current limited understanding of the downstream effects of sequestration (Figure 1). The challenge remains to bring the pieces of the puzzle together to figure out how the sequestration of the RBPs interplay to cause FXTAS pathology (Hagerman, 2012).

\section{RAN TRANSLATION IN FXTAS PATHOGENESIS}

In FXTAS pathogenesis, RAN protein toxicity plays a synergistic role with the RNA toxicity mechanism and offers a potential explanation for the presence of non-RBPs in the distinctive ubiquitin-positive intranuclear inclusions found in the brains of FXTAS patients. First discovered in CAG expansion constructs, RAN translation initiates in an AUG-independent manner and is known to occur in several repeat expansion disorders, among them Spinocerebellar Ataxia type 8 (SCA8), DM1 Frontotemporal Dementia (FTD), and ALS, as well as FXTAS (Zu et al., 2011, 2013; Ash et al., 2013; Mori et al., 2013). RAN translation initiation requires an $\mathrm{m}^{7} \mathrm{G}$ cap, the EIF4A helicase and $40 \mathrm{~S}$ ribosomal scanning and is strongly influenced by repeat length (Kearse et al., 2016). In CGG-induced RAN translation of FMR1 mRNA, initiation of translation is similar to canonical translation but only $30 \%-40 \%$ as efficient. The expanded premutation CGG repeat expansion induces AUG-independent RAN translation of FMRpolyG, which accumulates in the ubiquitin-positive intranuclear inclusions in transfected cells, FXTAS Drosophila, mouse models and patient brains (Todd et al., 2013). Out of three possible reading frames in the $5^{\prime}$ UTR of FMR1, RAN translation occurs in both the glycine (+1 frame) and alanine (+2 frame) reading frames, producing the FMRpolyglycine and FMRpolyalanine proteins, respectively, with no polyarginine product $(+0$ frame) detected as yet (Todd et al., 2013). However, only the polyglycine-containing

\section{FMR1 locus}

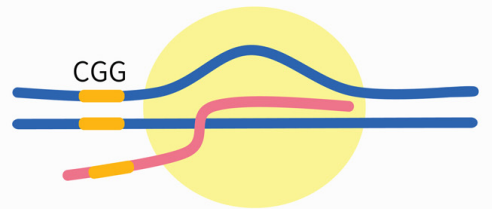

Transcription

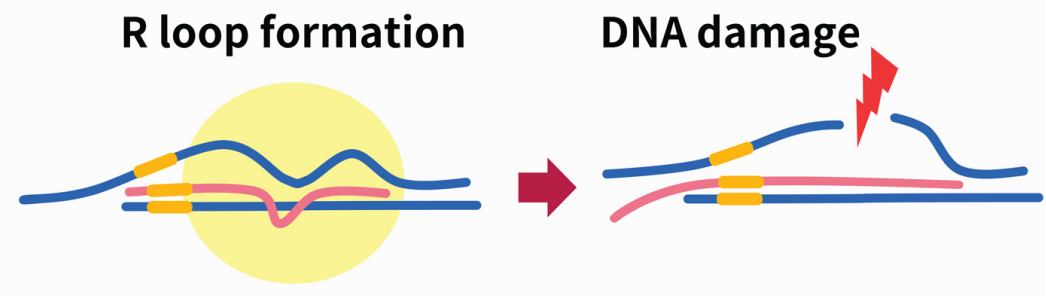

\section{Post-Transcription}

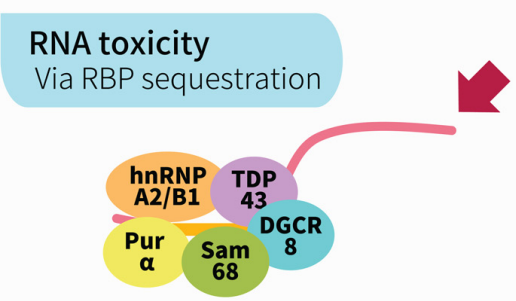

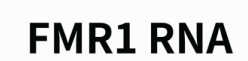

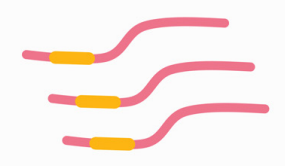

RAN protein toxicity

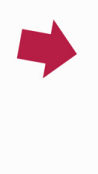

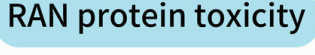

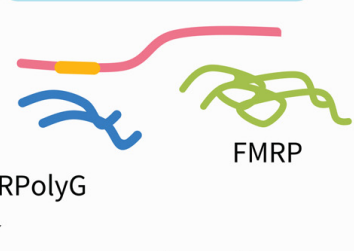

perturbed protein quality control

FIGURE 1 | Illustration of the main mechanisms of Fragile X-associated tremor/ataxia syndrome (FXTAS) pathogenesis. During transcription of the FMR1 locus, the formation of RNA:DNA hybrid R-loops through GC interaction of the expanded CGG repeats (depicted by yellow bar) can activate the DNA damage response and result in DNA breaks and the accumulation of $\gamma \mathrm{H} 2 \mathrm{AX}$. The two main mechanisms linked to FXTAS pathology are post-transcriptional. In the RNA toxicity mechanism, RNA-binding proteins (RBPs) are sequestered by the expanded CGG repeats, such as h2RNP A2/B1, Pur $\alpha$, Sam68, TDP43 and DGCR8; these are illustrated together for figurative purposes but do not necessarily form a complex simultaneously. In the RAN protein toxicity mechanism, the expanded CGG repeat induces AUG-independent RAN translation of FMRpolyG, which is found to form inclusions in patient brains as well as animal models of FXTAS. Other mechanisms not shown in this figure include the antisense transcript ASFMR1, mitochondrial dysfunction and 5hmC-mediated epigenetic modulation in FXTAS. 
protein, FMRpolyG, is detected in both cultured cells and animal models of FXTAS, and most importantly, in inclusions in FXTAS patient brains (Todd et al., 2013). Moreover, the expression of FMRpolyG is known to be toxic to Drosophila neurons, leading to retinal degeneration that can be enhanced by increasing FMRpolyG product and suppressed by eliminating RAN translation (Todd et al., 2013).

To determine the mechanism by which FMRpolyG production may contribute to FXTAS pathogenesis, Oh et al. (2015) examined ubiquitin-proteasome system (UPS) impairment in Drosophila and cell models of CGG repeatinduced toxicity. UPS impairment in FXTAS Drosophila led to enhanced neurodegeneration, whereas overexpression of HSP70 suppressed this toxicity. Furthermore, in cell models, the expression of FMRpolyG increased induction of UPS impairment, whereas prevention of RAN translation resulted in diminished UPS impairment (Oh et al., 2015). These findings indicate that RAN translation-induced FMRpolyG production may drive FXTAS pathogenesis by perturbing the protein quality control pathway through UPS failure (Oh et al., 2015).

Recently, researchers found that RAN translation also occurs from antisense FMR1 transcript containing CCG repeats from three different potential reading frames generating polyproline, polyarginine and polyalanine proteins. More importantly, these novel proteins are found to colocalize with ubiquitinated intranuclear inclusions in FXTAS patient neurons. These new findings provide additional support for RAN protein toxicity in FXTAS pathophysiology (Krans et al., 2016).

\section{OTHER MECHANISMS OF FXTAS PATHOGENESIS}

\section{R-Loop-Mediated DNA Damage}

In addition to post-transcriptional changes, there is evidence to suggest that the increase in FXTAS FMR1 RNA transcript results in molecular dysfunction at the transcriptional level. Loomis et al. (2014) have found that, upon transcription of the endogenous FMR1 locus, the nascent G-rich RNA transcribed from the GC-rich region of FMR1 5' UTR binds to the C-rich DNA template and forms a stable RNA: DNA hybrid, or R-loops (Reddy et al., 2011; Loomis et al., 2014). Notably, R-loop formation can be increased by enhanced transcription (Loomis et al., 2014). Excessive R-loop formation activates the DNA damage response and leads to DNA breaks, resulting in accumulation of $\gamma \mathrm{H} 2 \mathrm{AX}$, a histone variant associated with DNA damage repair that is also present in the inclusions of FXTAS patient neurons (Iwahashi et al., 2006; Hoem et al., 2011). These results clearly show that FXTAS pathology from the RNA toxicity mechanism may also occur co-transcriptionally via increased R-loop formation upon increased $F M R 1$ transcription, leading to subsequent DNA damage.

\section{Antisense Transcript: ASFMR1}

A lasting conundrum in the pathogenesis of FXTAS is that only a fraction of male premutation carriers develop FXTAS (Jacquemont et al., 2004), and there is considerable variability in the phenotype of FXTAS patients. Such observations raise the likelihood that FMR1 is not the sole gene responsible for FXTAS pathogenesis. In the search for alternate gene involvement, Ladd et al. (2007) identified an antisense transcript spanning the $F M R 1$ CGG repeat region in the antisense direction, which they dubbed the antisense transcript at the FMR1 locus, ASFMR1. Congruous to FMR1, ASFMR1 is upregulated in premutation carriers but silenced in the full-mutation range. Following transcription, ASFMR1 is spliced, and then transported to the cytoplasm. ASFMR1 transcription is driven by two alternative promoters: the FMR1 bidirectional promoter and the promoter in the second intron of FMR1. The latter is considered to be the major promoter in cells with premutation alleles and drives the transcription of the transcript, which spans the CGG repeat of the FMR1 gene in the CCG orientation and exhibits premutation-specific alternative splicing (Ladd et al., 2007). These findings strongly suggest that ASFRM1 is also implicated in the pathogenesis of FXTAS.

\section{Mitochondrial Dysfunction}

There is also evidence to indicate that FMR1 premutationassociated disorders, such as FXTAS and FXPOI, involve mitochondrial dysfunction. Using doxycycline (dox)-inducible transgenic mouse models expressing 90 CGGs in the RNA, Hukema et al. have found that dox-induced 90 CGG RNA-expressing mice not only experience loss of weight, death within 5 days, steatosis, and apoptosis in the liver, but that they also show altered expression of GPX1 and cytochrome C, markers of mitochondrial dysfunction (Hukema et al., 2014). Mitochondrial dysfunction is also seen in FXTAS human patients and mouse cultured cells. Along with decreased oxidative phosphorylation capacity, there is a defect in the import of mitochondrial proteins in premutation carriers (Napoli et al., 2011). Hippocampal neuronal cultures from premutation CGG knock-in mice exhibit mitochondrial abnormalities in the number, metabolic function and mobility of mitochondria (Kaplan et al., 2012). Mitochondrial abnormalities are also seen in granulosa cells and oocytes in a FXPOI mouse model, including reduced mitochondrial content, abnormal mitochondrial structure, and decreased expression of the mitochondrial genes $M f n 2$ and Opa1 (Conca Dioguardi et al., 2016). Hence, these findings point to mitochondrial dysfunction as another possible component of FXTAS pathology.

\section{5-hydroxymethylcytosine (5hmC)-Mediated Epigenetic Modulation}

Though initially regarded as only an intermediate of active DNA demethylation products (Pfaffeneder et al., 2011), 5 -hydroxymethylcytosine $(5 \mathrm{hmC})$ has gained attention more recently as an epigenetic modification with a significant role in processes like neurodevelopment and differentiation (Branco et al., 2011). $5 \mathrm{hmC}$ is converted from $5 \mathrm{mC}$ via catalysis by Ten-eleven translocation 1 (TET1), a 2-oxoglutarate (2OG)- and Fe (II)-dependent enzyme (Tahiliani et al., 2009). Our group has examined the global levels of $5 \mathrm{hmC}$ in the cerebella of rCGG mice compared to wild-type age-matched littermate controls (Yao et al., 2014). Significantly, 5hmC was reduced genome-wide in the cerebella of the rCGG mice, 
while several repetitive elements as well as cerebellum-specific enhancers exhibited increases in $5 \mathrm{hmC}$ levels. The differential 5-hydroxymethylated regions (DhMRs) were highly correlated with genes and transcription factors that play key roles in neuronal development. Furthermore, Esanov et al. (2016) have found that there is increased hydroxymethylation at the FMR1 promoter in the brains of FXS full-mutation patients compared to premutation carriers and unaffected controls. While these data support $5 \mathrm{hmC}$-mediated epigenetic modulation as a player in FXTAS pathogenesis, further studies, such as characterizing the level of $5 \mathrm{hmC}$ at the FMR1 locus, are warranted to reveal more about the role of the $5 \mathrm{hmC}$ mark in the pathogenic mechanism of FXTAS (Al-Mahdawi et al., 2014).

\section{THERAPEUTIC DEVELOPMENTS}

As there are still no effective treatment options for FXTAS, current therapeutic strategies are limited mainly to treatments aimed at ameliorating specific symptoms of FXTAS patients. Selective serotonin and norepinephrine reuptake inhibitors have been effective for anxiety and depression (Hagerman and Hagerman, 2015). Psychosis and tremor can be improved by atypical antipsychotics, such as propranolol and primidone (Zesiewicz et al., 2005; Muzar and Lozano, 2014). Although the NMDA receptor antagonist memantine, an FDA-approved compound for the treatment of Alzheimer's disease, did not show any significant improvement on tremors, balance problems, or executive function deficits in FXTAS patients compared to placebo (Seritan et al., 2014), verbal memory was improved when assessed by the event-related potential (ERP) paradigm in a subgroup of patients in a recent clinical trial (Yang J. C. et al., 2016). At the same time, however, the end goal is not mere symptomatic treatment, but rather effective treatments that target the pathogenic mechanism(s) of disease. Here we discuss some ongoing efforts to identify potential compounds and therapeutic targets in FXTAS both in vitro and in vivo (Figure 2).

MPEP and allopregnanolone, an mGluR antagonist and a GABA agonist, respectively, are potential therapeutics that may mitigate some of the RNA toxicity effects. Cortical astrocytes from mice expressing premutation CGG repeats display decreased expression of Glu transporters (GLT-1 and GLAST) and Glu uptake, and enhanced spontaneous asynchronous $\mathrm{Ca}^{2+}$ oscillations (Cao et al., 2013). An mGluR5 antagonist, 2-methyl6-(phenylethynyl)pyridine hydrochloride (MPEP), suppresses the intracellular $\mathrm{Ca}^{2+}$ increase induced by Glu (Cao et al., 2012, 2013). Although MPEP is neurotoxic to humans and cannot be used for therapy, these results shed light on Glu transport and $\mathrm{Ca}^{2+}$ signaling as potential targets for treatment. The natural neurosteroid allopregnanolone is a GABA signaling agonist, and it was found to ameliorate the clustered burst firing in hippocampal neurons from mice with FMR1 premutation alleles (Cao et al., 2012; Reddy and Rogawski, 2012). Allopregnanolone exhibits effective rescue in Alzheimer's disease mouse models and human cells, such as restoring learning and memory, in addition to improving neuronal proliferation and survival (Wang et al., 2010; Chen et al., 2011; Singh et al., 2012).
Allopregnanolone is already in use in Alzheimer's disease and traumatic brain injury clinical trials, making it a very likely treatment choice for FXTAS (Lozano et al., 2015).

In a chemical screen of efficient small molecules to suppress locomotion deficits and neurodegeneration of FXTAS Drosophila, several phospholipase A2 (PLA2) inhibitors were found to have significant effects, namely fluocinolone acetonide, quinacrine and arachidonyl trifluoromethyl ketone. These findings suggest a role for altered PLA2 activity in FXTAS and present a potential therapeutic target (Qurashi et al., 2012). Another potential target is the mammalian target of rapamycin (mTOR). Although the mTOR inhibitor rapamycin was shown to suppress neurotoxicity via autophagy activation in various neurodegenerative disease animal models, it can also enhance the neurodegeneration phenotypes in FXTAS Drosophila, such as aggravation of retinal degeneration and locomotion defects, as well as a shorter lifespan of flies (Lin et al., 2013). In contrast, genetic activation of mTOR signaling significantly suppresses the neurodegeneration phenotype (Lin et al., 2013).

Although a number of therapeutic strategies are being explored that specifically target some of the underlying pathogenic mechanisms of FXTAS discussed above, as of now targeted therapeutic development is far from clinical trials. Small molecules are being developed with a high affinity for rCGG hairpins that inhibit target proteins from binding to rCGG hairpins in vitro, thereby reducing the sequestration of RBPs by rCGG (Disney et al., 2012). Some compounds, such as 9-hydroxy-5,11-dimethyl-2-(2-(piperidin-1-yl)ethyl)-6Hpyrido[4, 3-b]carbazol-2-ium, improve pre-mRNA splicing deficits and reduce the number and size of CGG protein aggregates in FXTAS cells (Disney et al., 2012; Tran et al., 2014). Moreover, most recently, Yang W. Y. et al. (2016) reported the generation of designer, modularly assembled small molecules that bind rCGG expanded repeats and potently improve FXTAS-associated defects in cells.

Finally, in addition to small molecules, the histone acetyltransferase (HAT) inhibitors garcinol and anacardic acid have also been pursued as potential therapeutics for FXTAS. In an effort to understand why there is FMR1 mRNA buildup in FXTAS pathology, Todd et al. (2010) examined histone acetylation at the human FMR1 locus and found, interestingly, that histone acetylation was increased at the FMR1 locus in premutation carriers compared to control or FXS-derived cell lines, which correlated with increased FMR1 mRNA levels in premutation cell lines. This study went on to show that in premutation carrier cell lines, the HAT inhibitors garcinol and anacardic acid can repress FMR1 mRNA expression down to the level of control and can also extend the lifespan of Drosophila expressing the CGG repeat expansion (Todd et al., 2010). Based on these results, a novel mechanism was posited for the increased premutation FMR1 mRNA in FXTAS pathology. According to the proposed model, the expanded CGG repeats in FXTAS induces chromatin remodeling in cis, which leads to increased expression of FMR 1 mRNA. This study provides the basis for a new potential therapeutic strategy for FXTAS by using HDACs to control the increased expression of FMR1 mRNA-containing expanded CGG repeats. 


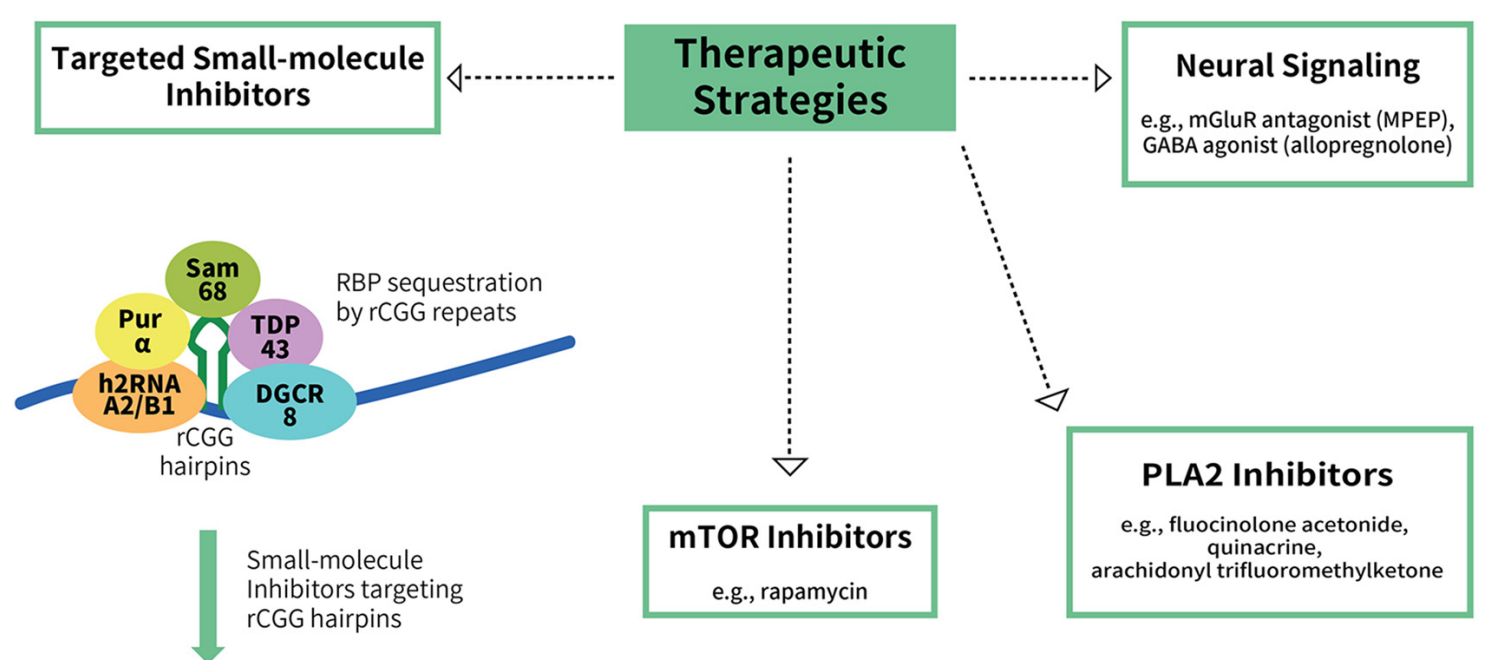

Reduced RBP sequestration

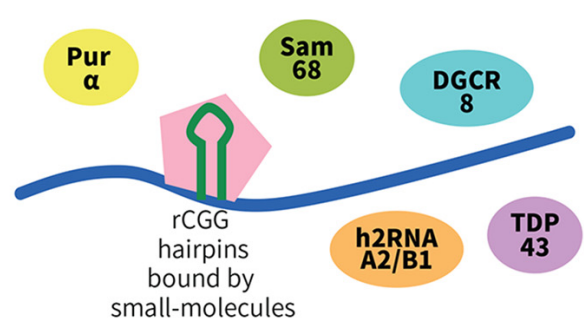

FIGURE 2 | Potential therapeutic strategies for FXTAS. To date, there are no treatments available for FXTAS. Therapeutic strategies explored include targeting the RBP sequestration mechanism of FXTAS pathogenesis, such as via the use of small-molecule inhibitors that bind to CGG hairpins with high affinity, thereby reducing the sequestration of the RBPs (Disney et al., 2012). Other potential targets include the mTOR inhibitor rapamycin, phospholipase A2 (PLA2) inhibitors, an mGluR antagonist (MPEP) and a GABA agonist (allopregnanolone).

Although it would be a challenge to bring these compounds to the bedside in the immediate future, development of these compounds enriches our understanding of therapeutic targets and extends the frontier of therapeutic development.

\section{PERSPECTIVE AND FUTURE DIRECTIONS}

Over the past decade, there has been considerable progress in our understanding of FXTAS and its pathogenesis. Two potential mechanistic models to explain the molecular pathogenesis of FXTAS have taken root and begun to solidify; namely, the RNA toxicity and the RAN protein toxicity mechanisms. In addition, we are beginning to develop a much more holistic understanding of other players in FXTAS pathogenesis, such as ASFMR1, mitochondrial dysfunction, and the implications of the 5hmC epigenetic mark (Ladd et al., 2007; Napoli et al., 2011; Kaplan et al., 2012; Hukema et al., 2014; Conca Dioguardi et al., 2016). However, much of our understanding of FXTAS pathogenesis is incomplete, and many questions remain unanswered.

Although we have identified numerous players in FXTAS pathogenesis, we still lack enough mechanistic and chronological understanding to identify the best targets for treatment. Indeed, in terms of chronology, studies in mice have shown that premutation expanded CGG repeats in the mouse Fmr1 gene perturb embryonic neocortical development (Cunningham et al., 2011). Also, in another study, cultured hippocampal neurons from mice expressing premutation CGG repeats exhibited shorter dendritic lengths and fewer branches between 7-21 days in vitro compared to wild-type littermates (Chen et al., 2010). These studies and others have raised the possibility that the onset of FXTAS may be the result of a lifelong pathologic process (Garcia-Arocena and Hagerman, 2010). If it is true that premutation carriers are predisposed to this lifelong pathologic process beginning in infancy, one of our next tasks would be to determine the factors that distinguish the premutation carriers who go on to develop FXTAS in late adulthood from those who are somehow protected. In addition, we would need to identify the earliest period for potential therapeutic intervention.

Variability in FXTAS is not limited to the onset of disease; there is also a broad spectrum of phenotypes (Garcia-Arocena and Hagerman, 2010). Although the main clinical manifestations remain locomotor in nature, FXTAS can also manifest as significant non-motor neurodegenerative phenotypes, such as 
cognitive decline/dementia and neuropsychiatric disturbances (Bourgeois et al., 2009; Garcia-Arocena and Hagerman, 2010). Adding to the phenotypic variability, in the low proportion of FXTAS patients who are female carriers, it is more common to see clinical features such as autoimmune-type dysfunction, hypothyroidism, and muscle pain than in men (Coffey et al., 2008; Garcia-Arocena and Hagerman, 2010). Thus, in addition to further decoding the molecular basis of FXTAS, subsequent efforts should be directed toward the identification of genetic modifiers that account for the variability in onset and phenotype seen with FXTAS.

\section{REFERENCES}

Al-Mahdawi, S., Virmouni, S. A., and Pook, M. A. (2014). The emerging role of 5-hydroxymethylcytosine in neurodegenerative diseases. Front. Neurosci. 8:397. doi: 10.3389/fnins.2014.00397

Arocena, D. G., Iwahashi, C. K., Won, N., Beilina, A., Ludwig, A. L., Tassone, F., et al. (2005). Induction of inclusion formation and disruption of lamin A/C structure by premutation CGG-repeat RNA in human cultured neural cells. Hum. Mol. Genet. 14, 3661-3671. doi: 10.1093/hmg/ddi394

Ash, P. E. A., Bieniek, K. F., Gendron, T. F., Caulfield, T., Lin, W.-L., Dejesus-Hernandez, M., et al. (2013). Unconventional translation of C9ORF72 GGGGCC expansion generates insoluble polypeptides specific to c9FTD/ALS. Neuron 77, 639-646. doi: 10.1016/j.neuron.2013. 02.004

Baloh, R. H. (2012). How do the RNA-binding proteins TDP-43 and FUS relate to amyotrophic lateral sclerosis and frontotemporal degeneration and to each other? Curr. Opin. Neurol. 25, 701-707. doi: 10.1097/WCO.0b013e32835a269b

Bond, A. T., Mangus, D. A., He, F., and Jacobson, A. (2001). Absence of Dbp2p alters both nonsense-mediated mRNA decay and rRNA processing. Mol. Cell. Biol. 21, 7366-7379. doi: 10.1128/mcb.21.21.7366-7379.2001

Bontekoe, C. J. M., Bakker, C. E., Nieuwenhuizen, I. M., van der Linde, H., Lans, H., de Lange, D., et al. (2001). Instability of a (CGG)98 repeat in the Fmr1 promoter. Hum. Mol. Genet. 10, 1693-1699. doi: 10.1093/hmg/10. 16.1693

Bourgeois, J. A., Coffey, S. M., Rivera, S. M., Hessl, D., Gane, L. W., Tassone, F., et al. (2009). A review of fragile $\mathrm{X}$ premutation disorders: expanding the psychiatric perspective. J. Clin. Psychiatry 70, 852-862. doi: 10.4088/JCP. $08 \mathrm{~m} 04476$

Branco, M. R., Ficz, G., and Reik, W. (2011). Uncovering the role of 5-hydroxymethylcytosine in the epigenome. Nat. Rev. Genet. 13, 7-13. doi: $10.1038 / \operatorname{nrg} 3080$

Cao, Z., Hulsizer, S., Cui, Y., Pretto, D. L., Kim, K. H., Hagerman, P. J., et al. (2013). Enhanced asynchronous $\mathrm{Ca}^{2+}$ oscillations associated with impaired glutamate transport in cortical astrocytes expressing Fmrl gene premutation expansion. J. Biol. Chem. 288, 13831-13841. doi: 10.1074/jbc.M112.441055

Cao, Z., Hulsizer, S., Tassone, F., Tang, H. T., Hagerman, R. J., Rogawski, M. A., et al. (2012). Clustered burst firing in FMR1 premutation hippocampal neurons: amelioration with allopregnanolone. Hum. Mol. Genet. 21, 2923-2935. doi: 10.1093/hmg/dds118

Chen, Y., Tassone, F., Berman, R. F., Hagerman, P. J., Hagerman, R. J., Willemsen, R., et al. (2010). Murine hippocampal neurons expressing Fmr1 gene premutations show early developmental deficits and late degeneration. Hum. Mol. Genet. 19, 196-208. doi: 10.1093/hmg/ddp479

Chen, S., Wang, J. M., Irwin, R. W., Yao, J., Liu, L., and Brinton, R. D. (2011). Allopregnanolone promotes regeneration and reduces $\beta$-amyloid burden in a preclinical model of Alzheimer's disease. PLoS One 6:e24293. doi: 10.1371/journal.pone.0024293

Coffey, S. M., Cook, K., Tartaglia, N., Tassone, F., Nguyen, D. V., Pan, R., et al. (2008). Expanded clinical phenotype of women with the FMR1 premutation. Am. J. Med. Genet. A 146A, 1009-1016. doi: 10.1002/ajmg.a.32060

Colak, D., Zaninovic, N., Cohen, M. S., Rosenwaks, Z., Yang, W. Y., Gerhardt, J., et al. (2014). Promoter-bound trinucleotide repeat mRNA drives epigenetic

\section{AUTHOR CONTRIBUTIONS}

HEK and JZ wrote the manuscript. SX edited it and provided the input. PJ and YJ edited the final version of the manuscript.

\section{ACKNOWLEDGMENTS}

The authors would like to thank C. Strauss for critical reading of the manuscript and DongJun Kim for help with the figures. This study was supported in part by grants from the National Institutes of Health (NS051630, NS079625 and NS091859 to PJ).

silencing in fragile X syndrome. Science 343, 1002-1005. doi: 10.1126/science. 1245831

Conca Dioguardi, C., Uslu, B., Haynes, M., Kurus, M., Gul, M., Miao, D. Q., et al. (2016). Granulosa cell and oocyte mitochondrial abnormalities in a mouse model of fragile X primary ovarian insufficiency. Mol. Hum. Reprod. 22, 384-396. doi: 10.1093/molehr/gaw023

Cronister, A., Teicher, J., Rohlfs, E. M., Donnenfeld, A., and Hallam, S. (2008) Prevalence and instability of fragile $\mathrm{X}$ alleles: implications for offering fragile X prenatal diagnosis. Obstet. Gynecol. 111, 596-601. doi: 10.1097/AOG. ob013e318163be0b

Cunningham, C. L., Martínez Cerdeño, V., Navarro Porras, E., Prakash, A. N., Angelastro, J. M., Willemsen, R., et al. (2011). Premutation CGG-repeat expansion of the Fmrl gene impairs mouse neocortical development. Hum. Mol. Genet. 20, 64-79. doi: 10.1093/hmg/ddq432

Denli, A. M., Tops, B. B. J., Plasterk, R. H. A., Ketting, R. F., and Hannon, G. J. (2004). Processing of primary microRNAs by the Microprocessor complex. Nature 432, 231-235. doi: 10.1038/nature03049

Disney, M. D., Liu, B., Yang, W. Y., Sellier, C., Tran, T., Charlet-Berguerand, N. et al. (2012). A small molecule that targets $\mathrm{r}(\mathrm{CGG})^{\exp }$ and improves defects in fragile X-associated tremor ataxia syndrome. ACS Chem. Biol. 7, 1711-1718. doi: 10.1021/cb300135h

Entezam, A., Biacsi, R., Orrison, B., Saha, T., Hoffman, G. E., Grabczyk, E., et al. (2007). Regional FMRP deficits and large repeat expansions into the full mutation range in a new Fragile X premutation mouse model. Gene 395, 125-134. doi: 10.1016/j.gene.2007.02.026

Esanov, R., Andrade, N. S., Bennison, S., Wahlestedt, C., and Zeier, Z. (2016). The FMR1 promoter is selectively hydroxymethylated in primary neurons of fragile X syndrome patients. Hum. Mol. Genet. 25, 4870-4880. doi: 10.1093/hmg/ddw311

Feng, Y., Zhang, F., Lokey, L. K., Chastain, J. L., Lakkis, L., Eberhart, D., et al. (1995). Translational suppression by trinucleotide repeat expansion at FMR1. Science 268, 731-734. doi: 10.1126/science.7732383

Galloway, J. N., Shaw, C., Yu, P., Parghi, D., Poidevin, M., Jin, P., et al. (2014). CGG repeats in RNA modulate expression of TDP-43 in mouse and fly models of fragile X tremor ataxia syndrome. Hum. Mol. Genet. 23, 5906-5915. doi: $10.1093 / \mathrm{hmg} / \mathrm{ddu} 314$

Garcia-Arocena, D., and Hagerman, P. J. (2010). Advances in understanding the molecular basis of FXTAS. Hum. Mol. Genet. 19, R83-R89. doi: $10.1093 / \mathrm{hmg} / \mathrm{ddq} 166$

Gokden, M., Al-Hinti, J. T., and Harik, S. I. (2009). Peripheral nervous system pathology in fragile $\mathrm{X}$ tremor/ataxia syndrome (FXTAS). Neuropathology 29, 280-284. doi: 10.1111/j.1440-1789.2008 00948.x

Greco, C. M., Berman, R. F., Martin, R. M., Tassone, F., Schwartz, P. H., Chang, A., et al. (2006). Neuropathology of fragile X-associated tremor/ataxia syndrome (FXTAS). Brain 129, 243-255. doi: 10.1093/brain/awh683

Greco, C. M., Hagerman, R. J., Tassone, F., Chudley, A. E., Del Bigio, M. R., Jacquemont, S., et al. (2002). Neuronal intranuclear inclusions in a new cerebellar tremor/ataxia syndrome among fragile X carriers. Brain 125, 1760-1771. doi: 10.1093/brain/awf184

Gregory, R. I., Yan, K.-P., Amuthan, G., Chendrimada, T., Doratotaj, B., Cooch, N., et al. (2004). The Microprocessor complex mediates the 
genesis of microRNAs. Nature 432, 235-240. doi: 10.1038/nature 03120

Hagerman, P. J. (2012). Current gaps in understanding the molecular basis of FXTAS. Tremor Other Hyperkinet. Mov. 2. doi: 10.7916/D80C4TH0

Hagerman, R. J., and Hagerman, P. J. (2002). The fragile X premutation: into the phenotypic fold. Curr. Opin. Genet. Dev. 12, 278-283. doi: 10.1016/s0959$437 x(02) 00299-x$

Hagerman, P. J., and Hagerman, R. J. (2015). Fragile X-associated tremor/ataxia syndrome. Ann. N Y Acad. Sci. 1338, 58-70. doi: 10.1111/nyas.12693

Hagerman, R. J., Leavitt, B. R., Farzin, F., Jacquemont, S., Greco, C. M., Brunberg, J. A., et al. (2004). Fragile-X-associated tremor/ataxia syndrome (FXTAS) in females with the FMR1 premutation. Am. J. Hum. Genet. 74, 1051-1056. doi: 10.1086/420700

Han, J., Lee, Y., Yeom, K.-H., Kim, Y.-K., Jin, H., and Kim, V. N. (2004). The Drosha-DGCR8 complex in primary microRNA processing. Genes Dev. 18, 3016-3027. doi: 10.1101/gad.1262504

Hashem, V., Galloway, J. N., Mori, M., Willemsen, R., Oostra, B. A., Paylor, R., et al. (2009). Ectopic expression of CGG containing mRNA is neurotoxic in mammals. Hum. Mol. Genet. 18, 2443-2451. doi: 10.1093/hmg/d dp 182

He, F., Krans, A., Freibaum, B. D., Taylor, J. P., and Todd, P. K. (2014). TDP-43 suppresses CGG repeat-induced neurotoxicity through interactions with HnRNP A2/B1. Hum. Mol. Genet. 23, 5036-5051. doi: 10.1093/hmg/d du2 216

Hoem, G., Raske, C. R., Garcia-Arocena, D., Tassone, F., Sanchez, E., Ludwig, A. L., et al. (2011). CGG-repeat length threshold for FMR1 RNA pathogenesis in a cellular model for FXTAS. Hum. Mol. Genet. 20, 2161-2170. doi: $10.1093 / \mathrm{hmg} / \mathrm{ddr} 101$

Hokkanen, S., Feldmann, H. M., Ding, H., Jung, C. K., Bojarski, L., Renner-Müller, I., et al. (2012). Lack of Pur-alpha alters postnatal brain development and causes megalencephaly. Hum. Mol. Genet. 21, 473-484. doi: $10.1093 / \mathrm{hmg} / \mathrm{ddr} 476$

Hukema, R. K., Buijsen, R. A., Raske, C., Severijnen, L. A., NieuwenhuizenBakker, I., Minneboo, M., et al. (2014). Induced expression of expanded CGG RNA causes mitochondrial dysfunction in vivo. Cell Cycle 13, 2600-2608. doi: 10.4161/15384101.2014.943112

Hukema, R. K., Buijsen, R. A., Schonewille, M., Raske, C., Severijnen, L. A., Nieuwenhuizen-Bakker, I., et al. (2015). Reversibility of neuropathology and motor deficits in an inducible mouse model for FXTAS. Hum. Mol. Genet. 24, 4948-4957. doi: 10.1093/hmg/ddv216

Hunsaker, M. R., Greco, C. M., Spath, M. A., Smits, A. P. T., Navarro, C. S., Tassone, F., et al. (2011). Widespread non-central nervous system organ pathology in fragile $\mathrm{X}$ premutation carriers with fragile $\mathrm{X}$-associated tremor/ataxia syndrome and CGG knock-in mice. Acta Neuropathol. 122, 467-479. doi: 10.1007/s00401-011-0860-9

Hunsaker, M. R., Wenzel, H. J., Willemsen, R., and Berman, R. F. (2009). Progressive spatial processing deficits in a mouse model of the fragile $\mathrm{X}$ premutation. Behav. Neurosci. 123, 1315-1324. doi: 10.1037/a0017616

Ishizuka, A., Siomi, M. C., and Siomi, H. (2002). A Drosophila fragile X protein interacts with components of RNAi and ribosomal proteins. Genes Dev. 16, 2497-2508. doi: 10.1101/gad.1022002

Iwahashi, C. K., Yasui, D. H., An, H. J., Greco, C. M., Tassone, F., Nannen, K., et al. (2006). Protein composition of the intranuclear inclusions of FXTAS. Brain 129, 256-271. doi: 10.1093/brain/awh650

Jacquemont, S., Hagerman, R. J., Leehey, M., Grigsby, J., Zhang, L., Brunberg, J. A., et al. (2003). Fragile X premutation tremor/ataxia syndrome: molecular, clinical, and neuroimaging correlates. Am. J. Hum. Genet. 72, 869-878. doi: $10.1086 / 374321$

Jacquemont, S., Hagerman, R. J., Leehey, M. A., Hall, D. A., Levine, R. A., Brunberg, J. A., et al. (2004). Penetrance of the fragile X-associated tremor/ataxia syndrome in a premutation carrier population. JAMA 291, 460-460. doi: 10.1001/jama.291.4.460

Jin, P., Duan, R., Qurashi, A., Qin, Y., Tian, D., Rosser, T. C., et al. (2007). Pur $\alpha$ binds to rCGG repeats and modulates repeat-mediated neurodegeneration in a Drosophila model of fragile X tremor/ataxia syndrome. Neuron 55, 556-564. doi: 10.1016/j.neuron.2007.07.020

Jin, P., Zarnescu, D. C., Zhang, F., Pearson, C. E., Lucchesi, J. C., Moses, K., et al. (2003). RNA-mediated neurodegeneration caused by the fragile X premutation rCGG repeats in Drosophila. Neuron 39, 739-747. doi: 10.1016/s0896-6273(03)00533-6

Kaplan, E. S., Cao, Z., Hulsizer, S., Tassone, F., Berman, R. F., Hagerman, P. J., et al. (2012). Early mitochondrial abnormalities in hippocampal neurons cultured from Fmr1 pre-mutation mouse model. J. Neurochem. 123, 613-621. doi: 10.1111/j.1471-4159.2012.07936.x

Kearse, M. G., Green, K. M., Krans, A., Rodriguez, C. M., Linsalata, A. E., Goldstrohm, A. C., et al. (2016). CGG repeat-associated non-AUG translation utilizes a cap-dependent scanning mechanism of initiation to produce toxic proteins. Mol. Cell 62, 314-322. doi: 10.1016/j.molcel.2016. 02.034

Kenneson, A., Zhang, F., Hagedorn, C. H., and Warren, S. T. (2001). Reduced FMRP and increased FMR1 transcription is proportionally associated with CGG repeat number in intermediate-length and premutation carriers. Hum. Mol. Genet. 10, 1449-1454. doi: 10.1093/hmg/10. 14.1449

Khalili, K., Del Valle, L., Muralidharan, V., Gault, W. J., Darbinian, N., Otte, J., et al. (2003). Pur $\alpha$ is essential for postnatal brain development and developmentally coupled cellular proliferation as revealed by genetic inactivation in the mouse. Mol. Cell. Biol. 23, 6857-6875. doi: 10.1128/mcb. 23.19.6857-6875.2003

Krans, A., Kearse, M. G., and Todd, P. K. (2016). Repeat-associated non-AUG translation from antisense CCG repeats in fragile $\mathrm{X}$ tremor/ataxia syndrome. Ann. Neurol. 80, 871-881. doi: 10.1002/ana.24800

Kremer, E. J., Pritchard, M., Lynch, M., Yu, S., Holman, K., Baker, E., et al. (1991). Mapping of DNA instability at the fragile $\mathrm{X}$ to a trinucleotide repeat sequence $\mathrm{p}(\mathrm{CCG}) \mathrm{n}$. Science 252, 1711-1714. doi: 10.1126/science.16 75488

Ladd, P. D., Smith, L. E., Rabaia, N. A., Moore, J. M., Georges, S. A., Hansen, R. S., et al. (2007). An antisense transcript spanning the CGG repeat region of FMR1 is upregulated in premutation carriers but silenced in full mutation individuals. Hum. Mol. Genet. 16, 3174-3187. doi: 10.1093/hmg/ddm293

Landthaler, M., Yalcin, A., and Tuschl, T. (2004). The human DiGeorge syndrome critical region gene 8 and its D. melanogaster homolog are required for miRNA biogenesis. Curr. Biol. 14, 2162-2167. doi: 10.1016/j.cub.2004. 11.001

Lee, Y., Ahn, C., Han, J., Choi, H., Kim, J., Yim, J., et al. (2003). The nuclear RNase III Drosha initiates microRNA processing. Nature 425, 415-419. doi: 10.1038/nature01957

Lin, Y., Tang, C., He, H., and Duan, R. (2013). Activation of mTOR ameliorates fragile $\mathrm{X}$ premutation rCGG repeat-mediated neurodegeneration. PLoS One 8:e62572. doi: 10.1371/journal.pone.0062572

Lin, C., Yang, L., Yang, J. J., Huang, Y., and Liu, Z.-R. (2005). ATPase/helicase activities of p68 RNA helicase are required for pre-mRNA splicing but not for assembly of the spliceosome. Mol. Cell. Biol. 25, 7484-7493. doi: 10.1128/mcb. 25.17.7484-7493.2005

Liu, Z.-R. (2002). p68 RNA helicase is an essential human splicing factor that acts at the U1 snRNA-5' splice site duplex. Mol. Cell. Biol. 22, 5443-5450. doi: $10.1128 / \mathrm{mcb} .22 .15 .5443-5450.2002$

Loomis, E. W., Sanz, L. A., Chédin, F., and Hagerman, P. J. (2014). Transcriptionassociated R-loop formation across the human FMR1 CGG-repeat region. PLoS Genet. 10:e1004294. doi: 10.1371/journal.pgen.1004294

Lozano, R., Martinez-Cerdeno, V., and Hagerman, R. J. (2015). Advances in the understanding of the gabaergic neurobiology of fmr1 expanded alleles leading to targeted treatments for fragile X spectrum disorder. Curr. Pharm. Des. 21, 4972-4979. doi: 10.2174/1381612821666150914121038

Mori, K., Weng, S.-M., Arzberger, T., May, S., Rentzsch, K., Kremmer, E., et al. (2013). The C9orf72 GGGGCC repeat is translated into aggregating dipeptiderepeat proteins in FTLD/ALS. Science 339, 1335-1338. doi: 10.1007/s00401013-1189-3

Muslimov, I. A., Patel, M. V., Rose, A., and Tiedge, H. (2011). Spatial code recognition in neuronal RNA targeting: role of RNA-hnRNP A2 interactions. J. Cell Biol. 194, 441-457. doi: 10.1083/jcb.201010027

Muzar, Z., and Lozano, R. (2014). Current research, diagnosis, and treatment of fragile X-associated tremor/ataxia syndrome. Intractable Rare Dis. Res. 3, 101-109. doi: 10.5582/irdr.2014.01029

Napoli, E., Ross-Inta, C., Wong, S., Omanska-Klusek, A., Barrow, C., Iwahashi, C., et al. (2011). Altered zinc transport disrupts mitochondrial 
protein processing/import in fragile X-associated tremor/ataxia syndrome. Hum. Mol. Genet. 20, 3079-3092. doi: 10.1093/hmg/ddr211

Oh, S. Y., He, F., Krans, A., Frazer, M., Taylor, J. P., Paulson, H. L., et al. (2015). RAN translation at CGG repeats induces ubiquitin proteasome system impairment in models of fragile X-associated tremor ataxia syndrome. Hum. Mol. Genet. 24, 4317-4326. doi: 10.1093/hmg/ddv165

Peier, A. M., and Nelson, D. L. (2002). Instability of a premutation-sized CGG repeat in FMR1 YAC transgenic mice. Genomics 80, 423-432. doi: $10.1006 /$ geno.2002.6849

Pfaffeneder, T., Hackner, B., Truß, M., Münzel, M., Müller, M., Deiml, C. A., et al. (2011). The discovery of 5-formylcytosine in embryonic stem cell DNA. Angew. Chem. Int. Ed Engl. 50, 7008-7012. doi: 10.1002/anie. 201103899

Pretto, D. I., Mendoza-Morales, G., Lo, J., Cao, R., Hadd, A., Latham, G. J., et al. (2014). CGG allele size somatic mosaicism and methylation in FMR1 premutation alleles. J. Med. Genet. 51, 309-318. doi: 10.1136/jmedgenet2013-102021

Qurashi, A., Li, W., Zhou, J. Y., Peng, J., and Jin, P. (2011). Nuclear accumulation of stress response mRNAs contributes to the neurodegeneration caused by Fragile X premutation rCGG repeats. PLoS Genet. 7:e1002102. doi: 10.1371/journal.pgen.1002102

Qurashi, A., Liu, H., Ray, L., Nelson, D. L., Duan, R., and Jin, P. (2012). Chemical screen reveals small molecules suppressing fragile $\mathrm{X}$ premutation $\mathrm{rCGG}$ repeatmediated neurodegeneration in Drosophila. Hum. Mol. Genet. 21, 2068-2075. doi: $10.1093 / \mathrm{hmg} / \mathrm{dds} 024$

Reddy, D. S., and Rogawski, M. A. (2012). "Neurosteroids- endogenous regulators of seizure susceptibility and role in the treatment of epilepsy," in Jasper's Basic Mechanisms of the Epilepsies 4th Edn., eds J. L. Noebels, M. Avoli, M. A. Rogawski, R. W. Olsen and A. V. Delgado-Escueta (Bethesda, MD: National Center for Biotechnology Information), 984-1002.

Reddy, K., Tam, M., Bowater, R. P., Barber, M., Tomlinson, M., Nichol Edamura, K., et al. (2011). Determinants of R-loop formation at convergent bidirectionally transcribed trinucleotide repeats. Nucleic Acids Res. 39, 1749-1762. doi: 10.1093/nar/gkq935

Rodriguez-Revenga, L., Madrigal, I., Pagonabarraga, J., Xunclà, M., Badenas, C., Kulisevsky, J., et al. (2009). Penetrance of FMR1 premutation associated pathologies in fragile X syndrome families. Eur. J. Hum. Genet. 17, 1359-1362. doi: 10.1038/ejhg.2009.51

Sellier, C., Freyermuth, F., Tabet, R., Tran, T., He, F., Ruffenach, F., et al. (2013). Sequestration of DROSHA and DGCR8 by expanded CGG RNA repeats alters microRNA processing in fragile $\mathrm{X}$-associated tremor/ataxia syndrome. Cell Rep. 3, 869-880. doi: 10.1016/j.celrep.2013. 02.004

Sellier, C., Rau, F., Liu, Y., Tassone, F., Hukema, R. K., Gattoni, R., et al. (2010). Sam68 sequestration and partial loss of function are associated with splicing alterations in FXTAS patients. EMBO J. 29, 1248-1261. doi: 10.1038/emboj. 2010.21

Seritan, A. L., Nguyen, D. V., Mu, Y., Tassone, F., Bourgeois, J. A., Schneider, A., et al. (2014). Memantine for fragile X-Associated tremor/ataxia syndrome. J. Clin. Psychiatry 75, 264-271. doi: 10.4088/JCP.13m 08546

Singh, C., Liu, L., Wang, J. M., Irwin, R. W., Yao, J., Chen, S., et al. (2012). Allopregnanolone restores hippocampal-dependent learning and memory and neural progenitor survival in aging $3 \times \mathrm{TgAD}$ and nonTg mice. Neurobiol. Aging 33, 1493-1506. doi: 10.1016/j.neurobiolaging.2011.06.008

Sofola, O. A., Jin, P., Qin, Y., Duan, R., Liu, H., de Haro, H. M., et al. (2007). RNA-binding proteins hnRNP A2/B1 and CUGBP1 suppress fragile X CGG premutation repeat-induced neurodegeneration in a Drosophila model of FXTAS. Neuron 55, 565-571. doi: 10.1016/j.neuron.2007. 07.021

Tahiliani, M., Koh, K. P., Shen, Y., Pastor, W. A., Bandukwala, H., Brudno, Y., et al. (2009). Conversion of 5-methylcytosine to 5-hydroxymethylcytosine in mammalian DNA by MLL partner TET1. Science 324, 930-935. doi: $10.1126 /$ science. 1170116

Tan, H., Poidevin, M., Li, H., Chen, D., and Jin, P. (2012a). MicroRNA277 modulates the neurodegeneration caused by Fragile X premutation rCGG repeats. PLoS Genet. 8:e1002681. doi: 10.1371/journal.pgen. 1002681
Tan, H., Qurashi, A., Poidevin, M., Nelson, D. L., Li, H., and Jin, P. (2012b). Retrotransposon activation contributes to fragile X premutation rCGG-mediated neurodegeneration. Hum. Mol. Genet. 21, 57-65. doi: $10.1093 / \mathrm{hmg} / \mathrm{ddr} 437$

Tassone, F., Hagerman, R. J., Taylor, A. K., Gane, L. W., Godfrey, T. E., and Hagerman, P. J. (2000). Elevated levels of FMR1 mRNA in carrier males: a new mechanism of involvement in the fragile-X syndrome. Am. J. Hum. Genet. 66, 6-15. doi: 10.1086/302720

Tassone, F., Iwahashi, C., and Hagerman, P. J. (2004). FMR1 RNA within the intranuclear inclusions of fragile $\mathrm{X}$-associated tremor/ataxia syndrome (FXTAS). RNA Biol. 1, 103-105. doi: 10.4161/rna.1. 2.1035

Timchenko, N. A., Cai, Z. J., Welm, A. L., Reddy, S., Ashizawa, T., and Timchenko, L. T. (2001). RNA CUG repeats sequester CUGBP1 and alter protein levels and activity of CUGBP1. J. Biol. Chem. 276, 7820-7826. doi: 10.1074/jbc.M005960200

Timchenko, L. T., Miller, J. W., Timchenko, N. A., DeVore, D. R., Datar, K. V., Lin, L., et al. (1996). Identification of a (CUG)n triplet repeat RNA-binding protein and its expression in myotonic dystrophy. Nucleic Acids Res. 24, 4407-4414. doi: 10.1093/nar/24.22.4407

Timchenko, N. A., Patel, R., Iakova, P., Cai, Z. J., Quan, L., and Timchenko, L. T. (2004). Overexpression of CUG triplet repeat-binding protein, CUGBP1, in mice inhibits myogenesis. J. Biol. Chem. 279, 13129-13139. doi: 10.1074/jbc. M312923200

Todd, P. K., Oh, S. Y., Krans, A., He, F., Sellier, C., Frazer, M., et al. (2013). CGG repeat-associated translation mediates neurodegeneration in fragile $\mathrm{X}$ tremor ataxia syndrome. Neuron 78, 440-455. doi: 10.1016/j.neuron.2013. 03.026

Todd, P. K., Oh, S. Y., Krans, A., Pandey, U. B., Di Prospero, N. A., Min, K. T., et al. (2010). Histone deacetylases suppress CGG repeatinduced neurodegeneration via transcriptional silencing in models of fragile $\mathrm{X}$ tremor ataxia syndrome. PLoS Genet. 6:e1001240. doi: 10.1371/journal.pgen.10 01240

Tran, T., Childs-Disney, J. L., Liu, B., Guan, L., Rzuczek, S., and Disney, M. D. (2014). Targeting the $\mathrm{r}(\mathrm{CGG})$ repeats that cause FXTAS with modularly assembled small molecules and oligonucleotides. ACS Chem. Biol. 9, 904-912. doi: $10.1021 / \mathrm{cb} 400875 \mathrm{u}$

Verkerk, A. J., Pieretti, M., Sutcliffe, J. S., Fu, Y. H., Kuhl, D. P., Pizzuti, A., et al. (1991). Identification of a gene (FMR-1) containing a CGG repeat coincident with a breakpoint cluster region exhibiting length variation in fragile X syndrome. Cell 65, 905-914. doi: 10.1016/0092-8674(91)9 0397-h

Wang, J. M., Singh, C., Liu, L., Irwin, R. W., Chen, S., Chung, E. J., et al. (2010). Allopregnanolone reverses neurogenic and cognitive deficits in mouse model of Alzheimer's disease. Proc. Natl. Acad. Sci. U S A 107, 6498-6503. doi: $10.1073 /$ pnas. 1001422107

Willemsen, R., Hoogeveen-Westerveld, M., Reis, S., Holstege, J., Severijnen, L. A. W. F. M., Nieuwenhuizen, I. M., et al. (2003). The FMR1 CGG repeat mouse displays ubiquitin-positive intranuclear neuronal inclusions; implications for the cerebellar tremor/ataxia syndrome. Hum. Mol. Genet. 12, 949-959. doi: 10.1093/hmg/ddg114

Williams, A. J., and Paulson, H. L. (2008). Polyglutamine neurodegeneration: protein misfolding revisited. Trends Neurosci. 31, 521-528. doi: 10.1016/j.tins. 2008.07.004

Wilson, B. J., Bates, G. J., Nicol, S. M., Gregory, D. J., Perkins, N. D., and FullerPace, F. V. (2004). The p68 and p72 DEAD box RNA helicases interact with $\mathrm{HDAC} 1$ and repress transcription in a promoter-specific manner. BMC Mol. Biol. 5:11. doi: 10.1186/1471-2199-5-11

Yang, W. Y., He, F., Strack, R. L., Oh, S. Y., Frazer, M., Jaffrey, S. R., et al. (2016). Small molecule recognition and tools to study modulation of $\mathrm{r}(\mathrm{CGG})^{\exp }$ in Fragile X-associated tremor ataxia syndrome. ACS Chem. Biol. 11, 2456-2465. doi: 10.1021/acschembio.6b00147

Yang, J. C., Rodriguez, A., Royston, A., Niu, Y.-Q., Avar, M., Brill, R., et al. (2016). Memantine improves attentional processes in fragile $\mathrm{X}$-associated tremor/ataxia syndrome: electrophysiological evidence from a randomized controlled trial. Sci. Rep. 6:21719. doi: 10.1038/srep21719

Yao, B., Lin, L., Street, R. C., Zalewski, Z. A., Galloway, J. N., Wu, H., et al. (2014). Genome-wide alteration of 5-hydroxymethylcytosine in a mouse model of 
fragile X-associated tremor/ ataxia syndrome. Hum. Mol. Genet. 23, 1095-1107. doi: $10.1093 / \mathrm{hmg} / \mathrm{ddt} 504$

Zesiewicz, T. A., Elble, R., Louis, E. D., Hauser, R. A., Sullivan, K. L., Dewey, R. B., et al. (2005). Practice parameter: therapies for essential tremor: report of the quality standards subcommittee of the american academy of neurology. Neurology 64, 2008-2020. doi: 10.1212/01.WNL.0000163769.28552.CD

Zu, T., Gibbens, B., Doty, N. S., Gomes-Pereira, M., Huguet, A., Stone, M. D., et al. (2011). Non-ATG-initiated translation directed by microsatellite expansions. Proc. Natl. Acad. Sci. U S A 108, 260-265. doi: 10.1073/pnas.10133 43108

Zu, T., Liu, Y., Bañez-Coronel, M., Reid, T., Pletnikova, O., Lewis, J., et al. (2013). RAN proteins and RNA foci from antisense transcripts in C9ORF72 ALS and frontotemporal dementia. Proc. Natl. Acad. Sci. U S A 110, E4968-E4977. doi: $10.1073 /$ pnas. 1315438110
Zühlke, C., Budnik, A., Gehlken, U., Dalski, A., Purmann, S., Naumann, M., et al. (2004). FMR1 premutation as a rare cause of late onset ataxia. J. Neurol. 251, 1418-1419. doi: 10.1007/s00415-004-0558-1

Conflict of Interest Statement: The authors declare that the research was conducted in the absence of any commercial or financial relationships that could be construed as a potential conflict of interest.

Copyright ( 2017 Kong, Zhao, Xu, Jin and Jin. This is an open-access article distributed under the terms of the Creative Commons Attribution License (CC BY). The use, distribution or reproduction in other forums is permitted, provided the original author(s) or licensor are credited and that the original publication in this journal is cited, in accordance with accepted academic practice. No use, distribution or reproduction is permitted which does not comply with these terms. 